\title{
Trends in incidence rate, health care consumption, and costs for patients admitted with a humeral fracture in The Netherlands between 1986 and 2012
}

Kiran C. Mahabier ${ }^{1}$, Dennis Den Hartog ${ }^{1}$, Joyce Van Veldhuizen ${ }^{1}$, Martien J.M. Panneman², Suzanne Polinder ${ }^{3}$, Michael H.J. Verhofstad ${ }^{1}$, Esther M.M. Van Lieshout ${ }^{1}$

${ }^{1}$ Trauma Research Unit Department of Surgery, Erasmus MC, University Medical Center Rotterdam, Rotterdam, The Netherlands

${ }^{2}$ Consumer Safety Institute, Amsterdam, The Netherlands

${ }^{3}$ Department of Public Health, Erasmus MC, Rotterdam, The Netherlands

\section{Corresponding author:}

Esther M.M. Van Lieshout

Erasmus MC, University Medical Center Rotterdam

Trauma Research Unit Department of Surgery

P.O. Box 2040, 3000 CA Rotterdam, The Netherlands

Phone: +31.10 .7031050$, Fax: +31.10 .7032396$

Mail: e.vanlieshout@erasmusmc.nl

Key words: epidemiology; incidence; health care costs; hospital costs; productivity loss; humeral fractures; shoulder fractures; proximal humerus, humeral shaft; distal humerus 


\section{ABSTRACT}

Introduction: This study aimed to examine long-term population-based trends in the incidence of patients with a humeral fracture admitted to a hospital in the Netherlands from 1986 to 2012 and to give a detailed overview of the health care consumption and productivity loss with associated costs.

Materials and Methods: Age and gender-standardized incidence rates of hospital admissions for patients with a proximal, shaft, or distal humeral fracture were calculated for each year (1986-2012). Injury cases, length of hospital stay (LOS), trauma mechanism, and operation rate were extracted from the National Medical Registration. An incidence-based cost model was applied to calculate costs for direct health care and lost productivity in 2012.

Results: Between 1986 and 2012 112,910 patients were admitted for a humeral fracture. The incidence rate increased from 17.8 in 1986 to 40.0 per 100,000 person years in 2012 . Incidence rates of proximal fractures increased the most, especially in elderly women. Operation rates decreased in patients aged 70 years or older. The mean LOS decreased from nine days in 1997 to five days in 2012. The cumulative LOS of all patients in 2012 was 28,880 days of which $73 \%$ were caused by women and $81 \%$ were 50 years or older. Cumulative medical costs in 2012 were M€55.4, of which M€43.4 was spent on women. Costs increased with age. Costs for hospital care contributed most to the overall costs per case until 70 years of age. From 70 years onwards, the main cost determinants were hospital care, rehabilitation/nursing care, and home care. Cumulative costs due to lost productivity were $M € 23.5$ in 2012. Costs per case increased with age in all anatomic regions. 
Conclusions: The crude number of patients admitted for a humeral fracture increased $124 \%$ in 27 years, and was associated with age and gender. Proximal fractures in elderly women accounted most significantly for this increase and most of the costs. The main cost determinants were hospital care and productivity loss. 


\section{INTRODUCTION}

Between 1986 and 2008, over 3.7 million persons presented to an Emergency Department (ED) of a Dutch hospital with an upper extremity injury; this comprised $42 \%$ of all ED visits in The Netherlands ${ }^{1}$. The incidence of upper extremity injuries overall increased by $13 \%$, from 970 in 1986 to 1,098 per 100,000 person years in 2008 , showing these injuries put an increasing pressure to resources. Incidence rates and health care use were related both to age and gender. In 2007, the total health care costs of upper extremity injuries in The Netherlands amounted $€ 290$ million. Fractures were the most expensive injuries to treat among upper extremity injuries, as $76 \%$ of the overall costs of the treatment were spent on the treatment of fracture patients ${ }^{1}$.

Given the sometimes permanent, disabling effect of humeral fractures, the societal burden associated with these injuries can be high ${ }^{2-4}$. Trauma affects persons of all ages and fractures in employed patients cause high costs for health care and lost productivity ${ }^{5,6}$. In current economic distress, insight into trends in incidence and costs of individual patient groups is highly relevant. Population-based knowledge of trends in incidence gives directions for the allocation of health care services and for preventive measures. Age and gender dependency of humeral fractures at the proximal end versus the shaft versus the distal end have not been described in detail yet. Likewise, detailed evaluations of costs, gaining insight in the parameters that contribute most to the overall costs, such as cost for hospital stay, physical therapy and rehabilitation, nursing care and costs due to productivity loss are not available. Due to budgetary restraints and increasing health care costs, such economic analyses are gaining importance.

Therefore, this study aimed to examine long-term population-based trends in the incidence of patients with a humeral fracture admitted to a hospital in the Netherlands from 1986 
to 2012 and to give a detailed overview of the associated costs for health care and lost productivity. 


\section{METHODS}

\section{Data source}

For this retrospective, epidemiological study data were collected for patients admitted to a hospital in The Netherlands with a humeral fracture in the period 1986-2012. In 2012 the Netherlands had 16.7 million inhabitants ${ }^{7}$. Injury cases were extracted from the National Medical Registration (LMR) of the Dutch Hospital Database (DHD), Utrecht, the Netherlands. The DHD collects hospital data of all hospitals in the Netherlands with a uniform classification system and has an almost complete national coverage (missing values $<5 \%$, except in 2007 12\%). These figures were extrapolated by the Consumer and Safety Institute to full national coverage for each year. An extrapolation factor was estimated by comparing the adherence population of the participating hospitals with the total Dutch population in each year using the population data obtained from Statistics Netherlands ${ }^{7,8}$. Patients are included in the LMR for their main diagnosis at discharge, defined by the International Classification of Diseases (ICD) 9th and (since 2010) 10th revision ${ }^{9}$. Codes for humeral fractures are presented in Table 1. Injuries include both traumatic and pathologic fractures.

The study was exempted by the local Medical Research Ethics Committee Erasmus MC (No. MEC-2014-120).

\section{Calculation of incidence rates}

Age- and gender-specific incidence rates were calculated in 5-year age groups for each year of the study. In order to adjust for differences in the demographic composition over time, incidence rates were standardized for age (in 5-year age groups) and gender using a direct standardization 
method, as previously described ${ }^{1}$. In short, the age- and sex-specific incidence rates per 100,000 person years were calculated based upon the Dutch mid-year standard population (calculated using the formula $\left(\left(\mathrm{N}_{1986}+\mathrm{N}_{2012}\right) / 2\right)$.

\section{Hospital length of stay, trauma mechanism, and surgical intervention}

Data regarding hospital length of stay (LOS), trauma mechanism, and operation rate were extracted from the LMR database for 10-year age categories. In order to assess trends in LOS and trauma mechanism over time, mean LOS and percentage of trauma mechanisms were averaged over 5-year intervals from 1993-2012. For operation rates, data were averaged over a 5year interval 2008-2012, as earlier data were not available.

\section{Direct and indirect health care costs}

The incidence-based Dutch Burden of Injury Model was used in order to measure and describe direct and indirect health care costs ${ }^{1,10-12}$. Patient numbers, health care consumption and related costs and costs for lost productivity were calculated using the LMR database and a patient follow-up survey on health care use ${ }^{13}$. Costs were measured from societal perspective and patients and patients were followed until two years after trauma. Medical costs included ambulance care, in-hospital care, general practitioner (G.P.) care, home care, physical therapy, and rehabilitation/nursing care. Health care costs were calculated by multiplying incidence and health care volumes with unit costs (e.g., costs per day in hospital). Unit costs were estimated according to national guidelines for health care costing ${ }^{14}$.

Costs for lost productivity were determined as described before ${ }^{12}$. Productivity costs were defined as the costs associated with production loss and replacement due to illness, disability, 
and premature death ${ }^{15}$. The absenteeism model was used in order to estimate costs for productivity loss for all patients aged 15-64 years. The friction cost method was used because health care needs are most substantial in the first year after injury for the majority of injuries ${ }^{16}$. Age-specific costs are presented in 10-year (medical costs) or 5-year (lost productivity) age groups for men and women separately. Data were averaged over 5-year intervals; 2002-2007 2008-2012, as earlier data were not available. Inflation has been taken into account. 


\section{RESULTS}

\section{Incidence rates}

During the study period 112,910 patients were admitted for a humeral fracture. The crude number of patients per year increased by $124 \%$; from 2,790 in 1986 to 6,250 in 2012 . The overall incidence rate increased from 17.8 per 100,000 person years (py) in 1986 to 40.0 per 100,000 py in 2012 . The increase in incidence rate was largest for proximal fractures $(20.0 / 100,000$ py in $2012 ;+277 \%)$, but was also noted for shaft fractures $(7.2 / 100,000$ py in $2012 ;+132 \%)$ and distal fractures $(12.8 / 100,000$ py in $2012 ;+36 \%$; Figure $1 \mathrm{~A})$. The largest increase was seen for proximal fractures in women since the year 2002.

The incidence rates showed a bimodal distribution, with a clear peak at 5-9 years of age for both genders and a gradual increase from 50 years onwards in women and from 65 years onwards in men (Figures 1B-C). Whereas the peak at 5-9 years has remained fairly stable during the study period (83.0/100,000 py for boys and 97.8/100,000 py for girls in 2012), the increase in the elderly has become more pronounced after the year 2002.

Figures 1D and E show incidence rates for the different age groups and anatomical regions in 2012 for men and women separately. Until 15 years of age, humeral fractures were mainly located at the distal end both in boys $(40.3 / 100,000$ py or $83 \%$ of total) and girls (47.2/100,000 py or $86 \%$ of total). From 50 years onwards, incidence rates of proximal, shaft, and distal fractures increased, especially in women. From 65 years, proximal fractures (33.1/100,00 py in men versus $119.1 / 100,000$ py in women) clearly outnumbered fractures at the shaft (9.7 versus 37.6/100,000 py), and distal end (6.5 versus 23.0/100,000 py). 


\section{Trauma mechanism}

Throughout the study period, falling was the dominant trauma mechanism at all ages. In 2012, falling caused $71 \%$ of proximal, $69 \%$ of shaft, and $79 \%$ of distal fractures in men. In women, these percentages were $82 \%, 81 \%$, and $80 \%$. The second most common mechanism was a traffic accident $(22 \%, 20 \%$, and $14 \%$ in men, and $15 \%, 13 \%$, and $17 \%$ in women, respectively).

\section{Operative treatment}

In 2012, operation rates for men and women of all ages combined were $62 \%$ for proximal, $67 \%$ for shaft, and $80 \%$ for distal fractures (Figure 2). For both genders, operation rates were fairly stable until 70 years, and decreased at older age. Overall, $73 \%$ of proximal fractures were operated in patients aged $<70$ years. At older age, operation rates decreased to $22 \%$ ( $24 \%$ in men, $22 \%$ in women) in the $90+$ age group. Of the shaft fractures, $72 \%$ were operated in patients aged $<70$ years, and decreased to $47 \%$ (50\% in men, $46 \%$ in women) in the oldest old. Distal fractures were operated most frequently; $81 \%$ in patients aged $<70$ years, decreasing to $48 \%$ (25\% in men, $52 \%$ in women) in the oldest old.

\section{Length of hospital stay}

The cumulative hospital LOS decreased from 34,050 days in 1997 to 28,880 days in 2012 . In four consecutive 5-year periods, the mean LOS per case increased with age, most significantly after 70 years (Figures 3A-B). Over time the mean LOS per case decreased in all age groups from nine days in 1997 to five days in 2012. The mean LOS per case in men and women admitted with a proximal fracture in 2012 was five days ( 4 days in patients $<70$ years and 7 days in patients aged 70 or older; Figures 3C-D). For patients with a shaft fracture mean LOS per case 
was five days ( 4 days at $<70$ years and 8 days at $70+$ ). For patients with a distal fractures, mean LOS per case was three days ( 2 and 8 days, respectively). LOS per case seemed unrelated to gender. The cumulative LOS in 2012 for men and women combined was 28,880 days, of which $73 \%$ were caused by women (Figures 3E-F). Of these hospital days $81 \%$ were caused by patients aged 50 years or older. Proximal fractures account for the largest part of the total LOS; 16,810 days versus 6,150 days for shaft and 5,920 days for distal fractures.

\section{Cost for health care consumption}

The cumulative medical costs for admitted patients increased from 47.8 million euro (M€) in 2007 to M€ 55.4 in 2012, of which approximately 75\% were caused by women (Table 2). The proximal humeral fractures accounted for the major part of the total costs (M€35.0 in 2012), while shaft and distal fractures were less expensive (M€10.6 and M€9.7, respectively). Costs per case were $€ 11,224$ for proximal, $€ 9,430$ for shaft, and $€ 4,858$ for distal fractures. In addition to costs per case being higher in women than in men (€10,383 versus $€ 5,796$ in 2012 for all fractures and age groups combined, see Table 2), costs consistently increased with age (Figure 4).

For each anatomic region, costs for hospital care contributed most to the overall cost per case until 70 years of age. From 70 years onwards, the main cost determinants were hospital care, rehabilitation/nursing care, and (most significantly in women) home care. For proximal fractures, overall costs per case until 70 years were $€ 6,111(€ 5,207$ for men versus $€ 6,620$ for women), of which $60 \%$ (68\% versus 56\%) were spent on hospital care. At ages $>70$ years, mean costs per case were $€ 17,119$ (€15,144 versus $€ 17,483)$, of which $39 \%$ (47\% versus $38 \%$ ) were spent on hospital care, $30 \%$ (30\% versus $30 \%)$ on rehabilitation/nursing care, and $25 \%$ (16\% 
versus $26 \%$ ) on home care. For shaft fractures, overall costs per case until 70 years were $€ 5,260$ ( 4,556 versus $€ 5,870$ for women), of which $66 \%$ ( $74 \%$ in men versus $61 \%$ in women) were spent on hospital care. At ages $>70$ years, mean costs per case were $€ 15,163(€ 12,039$ versus $€ 15,750$ ), of which $33 \%$ ( $40 \%$ versus $32 \%$ ) were spent on hospital care, $35 \%$ (36\% versus $35 \%$ ) on rehabilitation/nursing care, and 26\% (17\% versus $27 \%$ ) on home care. For distal fractures, overall costs per case until 70 years were $€ 3,393$ ( $€ 3,233$ for men versus $€ 3,540$ for women), of which $83 \%$ ( $87 \%$ in men versus $79 \%$ in women) were spent on hospital care. At ages $>70$ years, mean costs per case were $€ 13,7719$ ( $€ 11,908$ versus $€ 14,092$ ), of which $35 \%$ ( $41 \%$ versus $34 \%$ ) were spent on hospital care, $35 \%$ (37\% versus $35 \%$ ) on rehabilitation/nursing care, and $26 \%$ (17\% versus $27 \%)$ on home care.

\section{Costs for lost productivity}

For all anatomic regions, $>90 \%$ of patients had to take time off from work due to their humeral fracture, with no clear difference between men and women or across age groups. The cumulative number of days off work were 70,900 days in 2012 and were higher for proximal fractures (39,000 days) than for shaft (16,950 days) or distal (14,950 days) fractures. The associated cumulative costs for lost productivity were M€23.5 (€13.5, M€5.4, and M€4.6, respectively), with consistently higher total costs as well as costs per case for men (Table 3). The costs per case gradually increased with age in all anatomic regions to more than $€ 25,000$ in men and more than $€ 19,000$ in women aged 60 years or older (Figures $5 \mathrm{~A}$ and B). Due to differences in incidence rates, cumulative costs were highest for patients with a proximal fracture, with a peak for men aged 50-54 years (M€1.5) and women aged 55-59 years (M€2.1). 


\section{DISCUSSION}

In the 27 year study period, the crude number of patients increased by $124 \%$ to 112,910 patients in 2012. Incidence rates, health care consumption, and direct and indirect costs were all associated with anatomic region, age, and gender.

The increase in humeral fractures over time in general may be attributable to population ageing, with increasing numbers of elderly (women) being at risk for fractures due to osteoporosis $^{17}$. The incidence rate of proximal humeral fractures of 20.0/100,000 person years in 2012 is somewhat lower than published ${ }^{18}$, although that study included patients from the age of 15 years. The incidence rate of proximal fractures increased mostly in women, similar to studies from Finland and Austria ${ }^{19-21}$. The even faster increase in clinical admissions since 2002 may also be attributable to introduction of new and development of existing locking plates resulting in new technologies and techniques. Increased operation rates since 2002 has been described before in a single-center study from the $\mathrm{US}^{22}$ and, especially for women, also in a Finnish population $\operatorname{study}^{23}$.

Similarly, development of new plating options may explain the increase in admissions of patients with shaft fractures, which was also reported for the Finnish population ${ }^{24}$. These new options may have resulted in operative treatment of patients that would previously have been treated nonoperatively, not requiring hospitalization. Both in their and our study, this effect was most noticeable in women and the older age groups. The incidence rate for humeral shaft fractures of seven per 100,000 person years is in line with published data ${ }^{18}$. The current data also confirm the known bimodal age distribution, with a peak in the age group 20-24 and a gradual 
increase from 50 years onwards ${ }^{25,26}$. In the current study, however, the peak in young adult women was less pronounced.

Distal humeral fractures account for the biggest share of humeral fractures in children, with a peak in the age groups 5-9. This is in line with the reported average age of 6.8 years ${ }^{27}$. The incidence rate (13/100,000 person years) in the current study was slightly higher than the 9/100,000 person years published for patients aged 15 years or older ${ }^{18}$.

As reported before, falling was the dominant trauma mechanism for all three types of humeral fractures ${ }^{25,26,28,29}$. This supports the relevance of fall prevention strategies as a measure to reduce the number of fractures ${ }^{30}$.

Since 1993 LOS decreased from nine to five days per case. Previous data (13.8 days in 1989 and 9.3 days in 2013) seem to support this trend ${ }^{31,32}$. The 9.3 days was reported for patients admitted to a regional trauma center only, which may explain their seemingly longer hospital stay $^{31}$. Although this decrease is most likely due to changing hospital protocols and care pathways (aimed at earlier transfer to nursing or rehabilitation facilities), current data are not suitable to confirm this. Despite increasing incidence rates, the decrease in LOS per case was paralleled by a decrease in the cumulative LOS over time. Elderly women with a proximal humeral fracture contributed most significantly to the cumulative LOS. As costs for hospital stay are only a part of the total medical costs, reduced LOS did not cause a reduction in medical costs.

Current data showed that medical costs increased with age. This has not been reported before. Main cost determinants were hospital care, and rehabilitation/nursing care and home care. The finding that especially elderly women need more home care might reflect that women tend to outlive their partners and elderly are more prone to losing their independence after sustaining an injury. Polinder et al. reported lower costs per case for upper arm fractures in 2007 
$(€ 4,440)$ than the current study in $2012(€ 8,644)^{1}$. However, that study also included nonadmitted patients. Previous studies reported total costs without providing the cost components as done in the current study ${ }^{1,10}$.

A strength of our study is that it is population-based, offering long-term trends. National registry data are more reliable in representing true health care problems than extrapolating data from a single study or hospital. In addition, as the rate of missing data was fairly stable over time, trends noted are unlikely due to changes in coding and documentation. Data are reported for humeral fractures as a whole, but also for specific anatomical regions. Moreover, age and gender-dependent trends were evaluated. This study presented detailed information on health care and lost productivity costs in patients admitted for a humeral fracture. To the best of our knowledge, this has not been previously described.

We acknowledge limitations, the most obvious being that this study only included admitted patients. The LMR database only contains information about admitted patients. A national database that records all Emergency Department attendances exists, but there is no unique code for extracting the data for humeral fractures as a whole, nor per anatomical region. In that database humeral fractures are pooled together with fractures of the clavicle and scapula. In addition, the ICD coding system is the same for traumatic and pathological fractures, making it impossible to exclude the pathological fractures. Also, as patients are recorded based on the main injury at discharge underreporting might occurred in patients with multiple injuries. 


\section{CONCLUSION}

This study showed an increase of $124 \%$ in absolute numbers of patients admitted for humeral

fractures in the last 27 years. This increase was associated with age and gender. Proximal

fractures in elderly women accounted most significantly for this increase and most of the costs.

This insight in direct and indirect medical costs and costs for lost productivity offer tools for cost reduction and give direction to future demands.

\section{SOURCE OF FUNDING}

No external funding was received for this study. 


\section{REFERENCES}

1 Polinder S, Iordens GIT, Panneman MJM, Eygendaal D, Patka P, Den Hartog D, et al. Trends in incidence and costs of injuries to the shoulder, arm and wrist in The Netherlands between 1986 and 2008. BMC Public Health 2013;13:531.

2 Murray IR, Amin AK, White TO, Robinson CM. Proximal humeral fractures: current concepts in classification, treatment and outcomes. J Bone Joint Surg Br 2011;93:1-11.

3 Walker M, Palumbo B, Badman B, Brooks J, Van Gelderen J, Mighell M. Humeral shaft fractures: a review. J Shoulder Elbow Surg 2011;20:833-44.

4 Nauth A, McKee MD, Ristevski B, Hall J, Schemitsch EH. Distal humeral fractures in adults. J Bone Joint Surg Am 2011;93:686-700.

5 Bonafede M, Espindle D, Bower AG. The direct and indirect costs of long bone fractures in a working age US population. J Med Econ 2013;16:169-78.

6 Kilgore ML, Morrisey MA, Becker DJ, Gary LC, Curtis JR, Saag KG, et al. Health care expenditures associated with skeletal fractures among Medicare beneficiaries, 1999-2005. J Bone Miner Res 2009;24:2050-5.

7 Bevolking. CBS Nederland; 2014.

8 Van Der Stegen RHM, Ploemacher J. Description of methods for statistics by diagnoses in time by using the LMR (1981-2005) [Methodebeschrijving van tijdreeks diagnose statistieken op basis van de LMR 1981-2005]. The Hague, The Netherlands: Statistics Netherlands (CBS). ; 2009.

9 International Classification of Diseases (ICD). World Health Organization; 2010.

10 Meerding WJ, Mulder S, van Beeck EF. Incidence and costs of injuries in The Netherlands. Eur J Public Health 2006;16:272-8. 
11 Polinder S, Meerding WJ, van Baar ME, Toet H, Mulder S, van Beeck EF, et al. Cost estimation of injury-related hospital admissions in 10 European countries. J Trauma 2005;59:1283-90; discussion 90-1.

12 De Putter CE, Selles RW, Polinder S, Panneman MJ, Hovius SE, van Beeck EF. Economic impact of hand and wrist injuries: health-care costs and productivity costs in a population-based study. J Bone Joint Surg Am 2012;94:e56.

13 Polinder S, van Beeck EF, Essink-Bot ML, Toet H, Looman CW, Mulder S, et al. Functional outcome at 2.5, 5, 9, and 24 months after injury in the Netherlands. J Trauma 2007;62:133-41.

14 The Dutch Burden of Injury Model. Amsterdam, The Netherlands: Consumer and Safety Institute; 2010.

15 Koopmanschap MA, Rutten FF, van Ineveld BM, van Roijen L. The friction cost method for measuring indirect costs of disease. J Health Econ 1995;14:171-89.

16 Van Beeck EF, Van Roijen L, Mackenbach JP. Medical costs and economic production losses due to injuries in the Netherlands. J Trauma 1997;42:1116-23.

17 Cummings SR, Melton LJ. Epidemiology and outcomes of osteoporotic fractures. Lancet 2002;359:1761-7.

18 Somersalo A, Paloneva J, Kautiainen H, Lonnroos E, Heinanen M, Kiviranta I. Incidence of fractures requiring inpatient care. Acta Orthop 2014;85.

19 Kannus P, Palvanen M, Niemi S, Sievanen H, Parkkari J. Rate of proximal humeral fractures in older Finnish women between 1970 and 2007. Bone 2009;44:656-9. 
20 Dimai HP, Svedbom A, Fahrleitner-Pammer A, Pieber T, Resch H, Zwettler E, et al. Epidemiology of proximal humeral fractures in Austria between 1989 and 2008. Osteoporos Int 2013;24:2413-21.

21 Palvanen M, Kannus P, Niemi S, Parkkari J. Update in the epidemiology of proximal humeral fractures. Clin Orthop Relat Res 2006;442:87-92.

22 Bell JE, Leung BC, Spratt KF, Koval KJ, Weinstein JD, Goodman DC, et al. Trends and variation in incidence, surgical treatment, and repeat surgery of proximal humeral fractures in the elderly. J Bone Joint Surg Am 2011;93:121-31.

23 Huttunen TT, Launonen AP, Pihlajamaki H, Kannus P, Mattila VM. Trends in the surgical treatment of proximal humeral fractures - a nationwide 23-year study in Finland. BMC Musculoskelet Disord 2012;13:261.

24 Huttunen TT, Kannus P, Lepola V, Pihlajamaki H, Mattila VM. Surgical treatment of humeral-shaft fractures: a register-based study in Finland between 1987 and 2009. Injury 2012;43:1704-8.

25 Tytherleigh-Strong G, Walls N, McQueen MM. The epidemiology of humeral shaft fractures. J Bone Joint Surg Br 1998;80:249-53.

26 Ekholm R, Adami J, Tidermark J, Hansson K, Tornkvist H, Ponzer S. Fractures of the shaft of the humerus. An epidemiological study of 401 fractures. J Bone Joint Surg Br 2006;88:1469-73.

27 Rennie L, Court-Brown CM, Mok JY, Beattie TF. The epidemiology of fractures in children. Injury 2007;38:913-22. 
28 Robinson CM, Hill RM, Jacobs N, Dall G, Court-Brown CM. Adult distal humeral metaphyseal fractures: epidemiology and results of treatment. J Orthop Trauma $2003 ; 17: 38-47$.

29 Court-Brown CM, Garg A, McQueen MM. The epidemiology of proximal humeral fractures. Acta Orthop Scand 2001;72:365-71.

30 Palvanen M, Kannus P, Piirtola M, Niemi S, Parkkari J, Jarvinen M. Effectiveness of the Chaos Falls Clinic in preventing falls and injuries of home-dwelling older adults: a randomised controlled trial. Injury 2014;45:265-71.

31 Bercik MJ, Tjoumakaris FP, Pepe M, Tucker B, Axelrad A, Ong A, et al. Humerus fractures at a regional trauma center: an epidemiologic study. Orthopedics 2013;36:e8917.

32 Lind T, Kroner K, Jensen J. The epidemiology of fractures of the proximal humerus. Arch Orthop Trauma Surg 1989;108:285-7. 
TABLES AND FIGURES

Table 1. Humeral fractures classified in ICD-9 and ICD-10

\begin{tabular}{llll}
\hline Fracture region & Fracture closed or open & ICD-9 & ICD-10 \\
\hline Proximal & $\begin{array}{l}\text { Fracture of upper end of humerus } \\
\text { closed }\end{array}$ & 812.0 & $\mathrm{~S} 42.2$ \\
& $\begin{array}{l}\text { Fracture of upper end of humerus } \\
\text { open }\end{array}$ & 812.1 & $\mathrm{~S} 42.2$ \\
\hline Shaft & $\begin{array}{l}\text { Closed fracture of shaft or } \\
\text { unspecified part of humerus }\end{array}$ & 812.2 & $\mathrm{~S} 42.3$ \\
& $\begin{array}{l}\text { Fracture of shaft or unspecified } \\
\text { part of humerus open }\end{array}$ & 812.3 & $\mathrm{~S} 42.3$ \\
\hline Distal & $\begin{array}{l}\text { Fracture of lower end of humerus } \\
\text { closed }\end{array}$ & 812.4 & $\mathrm{~S} 42.4$ \\
& $\begin{array}{l}\text { Fracture of lower end of humerus } \\
\text { open }\end{array}$ & 812.5 & $\mathrm{~S} 42.4$ \\
\hline
\end{tabular}


Table 2: Medical costs per case and cumulative costs by anatomical region and gender in 2012

\begin{tabular}{lcccc}
\hline & Proximal & Shaft & Distal & Total \\
\hline Men & & & & \\
N & 828 & 378 & 861 & 2,067 \\
Cost/case $(€)$ & 7,913 & 6,043 & 3,650 & 5,796 \\
$\quad$ Total cost $(\mathrm{M} €)$ & 6.6 & 2.3 & 3.1 & 12.0 \\
Women & & & & \\
N & 2,293 & 749 & 1,136 & 4,179 \\
Cost/case $(€)$ & 12,420 & 11,140 & 5,773 & 10,383 \\
$\quad$ Total cost $(\mathrm{M} €)$ & 28.5 & 8.3 & 6.6 & 43.4 \\
Overall (men + women) & & & & \\
$\quad \mathrm{N}$ & 3,121 & 1,128 & 1,997 & 6,246 \\
Cost/case $(€)$ & 11,224 & 9,430 & 4,858 & 8,864 \\
Total cost $(\mathrm{M} €)$ & 35.0 & 10.6 & 9.7 & 55.4 \\
\hline
\end{tabular}


Table 3: Absenteeism and associated costs for lost productivity by anatomical region and gender in 2012

\begin{tabular}{lcccc}
\hline & Proximal & Shaft & Distal & Total \\
\hline Men & & & & \\
Employed $^{\mathrm{A}}$ & $343(78)$ & $174(75)$ & $159(75)$ & $676(76)$ \\
Cost/case $(€)$ & 22,383 & 19,256 & 19,464 & 20,890 \\
Total cost $(\mathrm{M} €)$ & 7.1 & 3.1 & 2.9 & 13.1 \\
Women & & & & \\
Employed & $369(54)$ & $139(61)$ & $109(59)$ & $317(56)$ \\
Cost/case $(€)$ & 18,506 & 17,681 & 17,339 & 18,114 \\
Total cost $(\mathrm{M} €)$ & 6.3 & 2.3 & 1.8 & 10.4 \\
Overall $\left(\right.$ men + women) $_{\text {Employed }}^{\mathrm{A}}$ & & & & \\
Cost $_{\text {case }(€)}$ & $712(63)$ & $313(68)$ & $269(68)$ & $1,293(65)$ \\
Total cost $(\mathrm{M} €)$ & 20,374 & 18,558 & 18,598 & 19,566 \\
& 13.5 & 5.4 & 4.640 & 23.5 \\
\hline
\end{tabular}

${ }^{\mathrm{A}}$ Data are shown as number (\%). 
Figure 1. Age-related incidence rates (per 100,000 person years) of humeral fractures overall (A), in males $(\mathrm{B}, \mathrm{D})$, and in females $(\mathrm{C}, \mathrm{E})$

Data are shown by anatomical region (A, D, E) and year (B, C). Figures 1D and E show data for 2012.

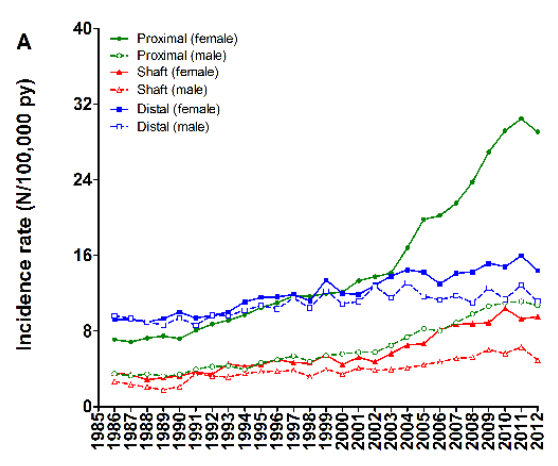

Year
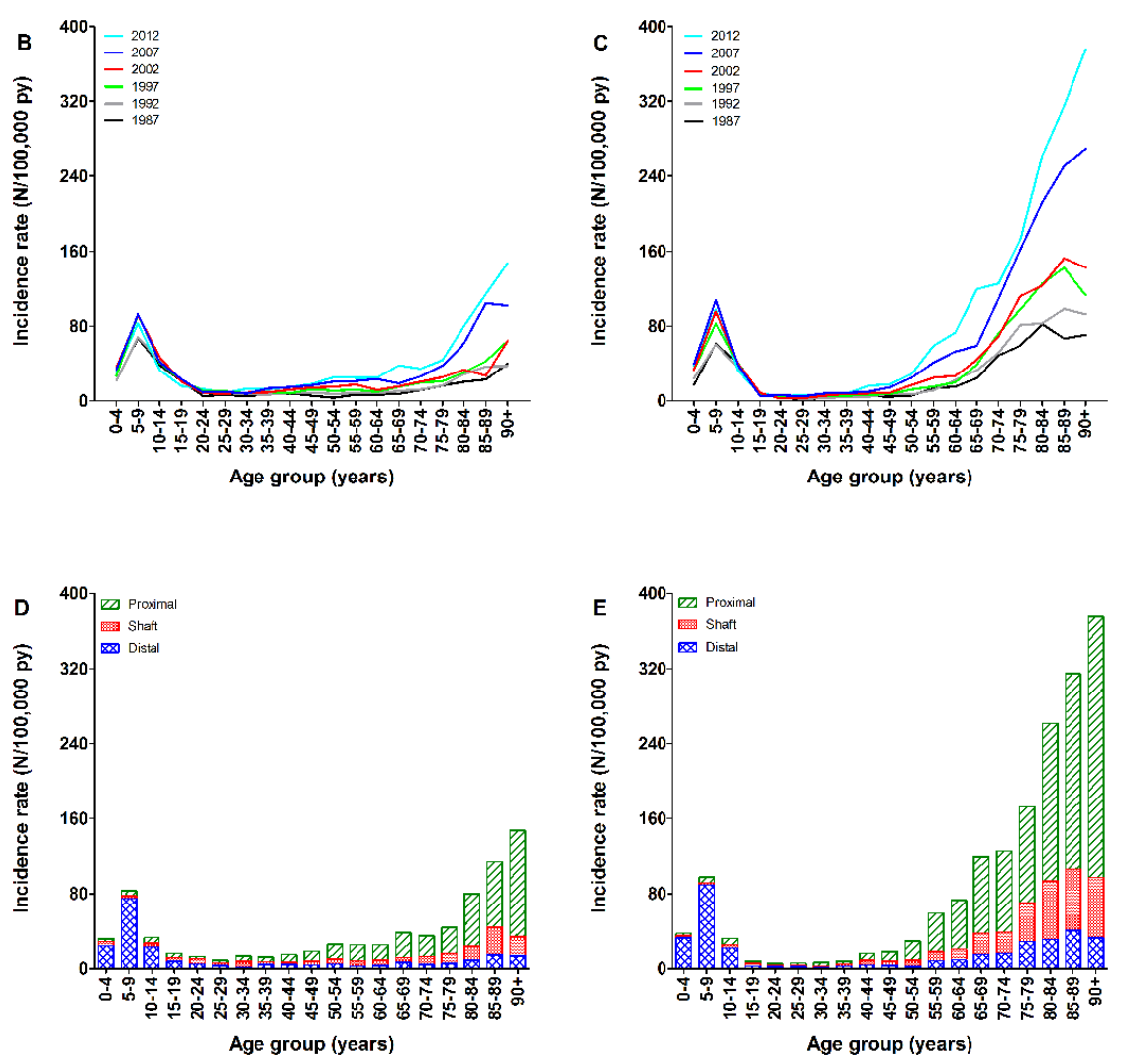
Figure 2. Age-related percentage of patients undergoing surgical treatment in males and

\section{females}

Data are shown by anatomical region for 2012 .

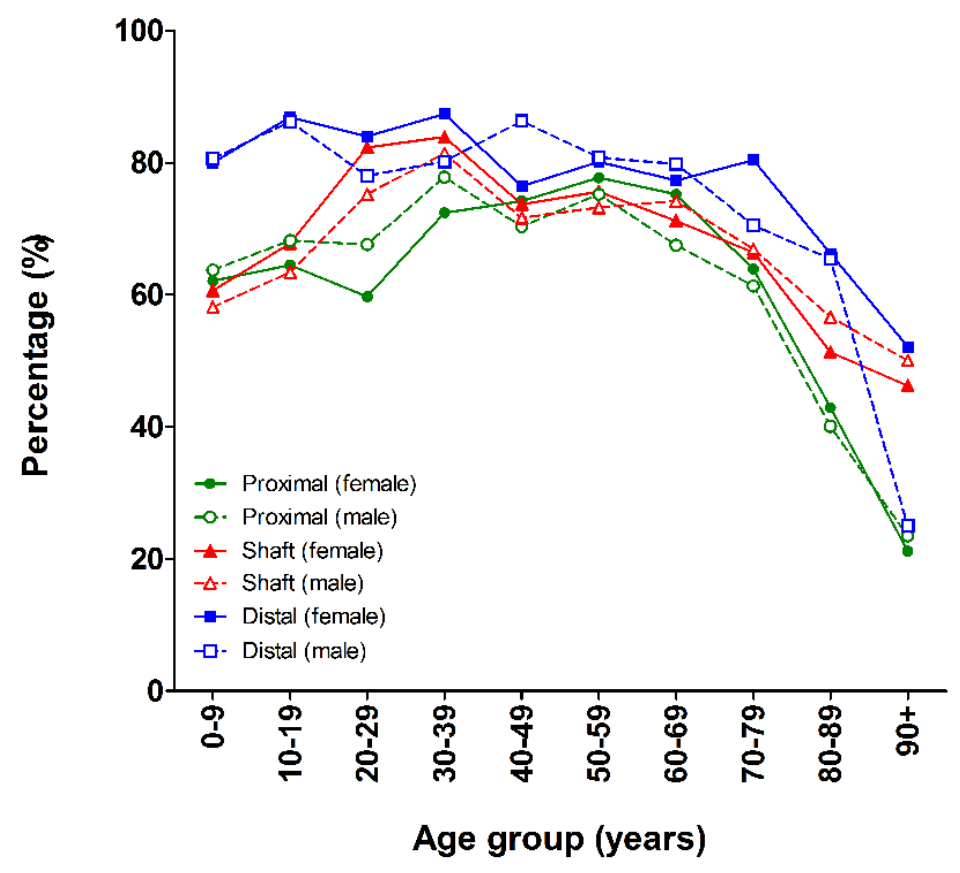


Figure 3. Hospital length of stay in males $(\mathrm{A}, \mathrm{C}, \mathrm{E})$ and females $(\mathrm{B}, \mathrm{D}, \mathrm{F})$

Figures $\mathrm{A}$ and $\mathrm{B}$ show data of the entire humerus for four different time periods. Figures $4 \mathrm{C}$ to $\mathrm{F}$ show data by anatomical region for 2012 .
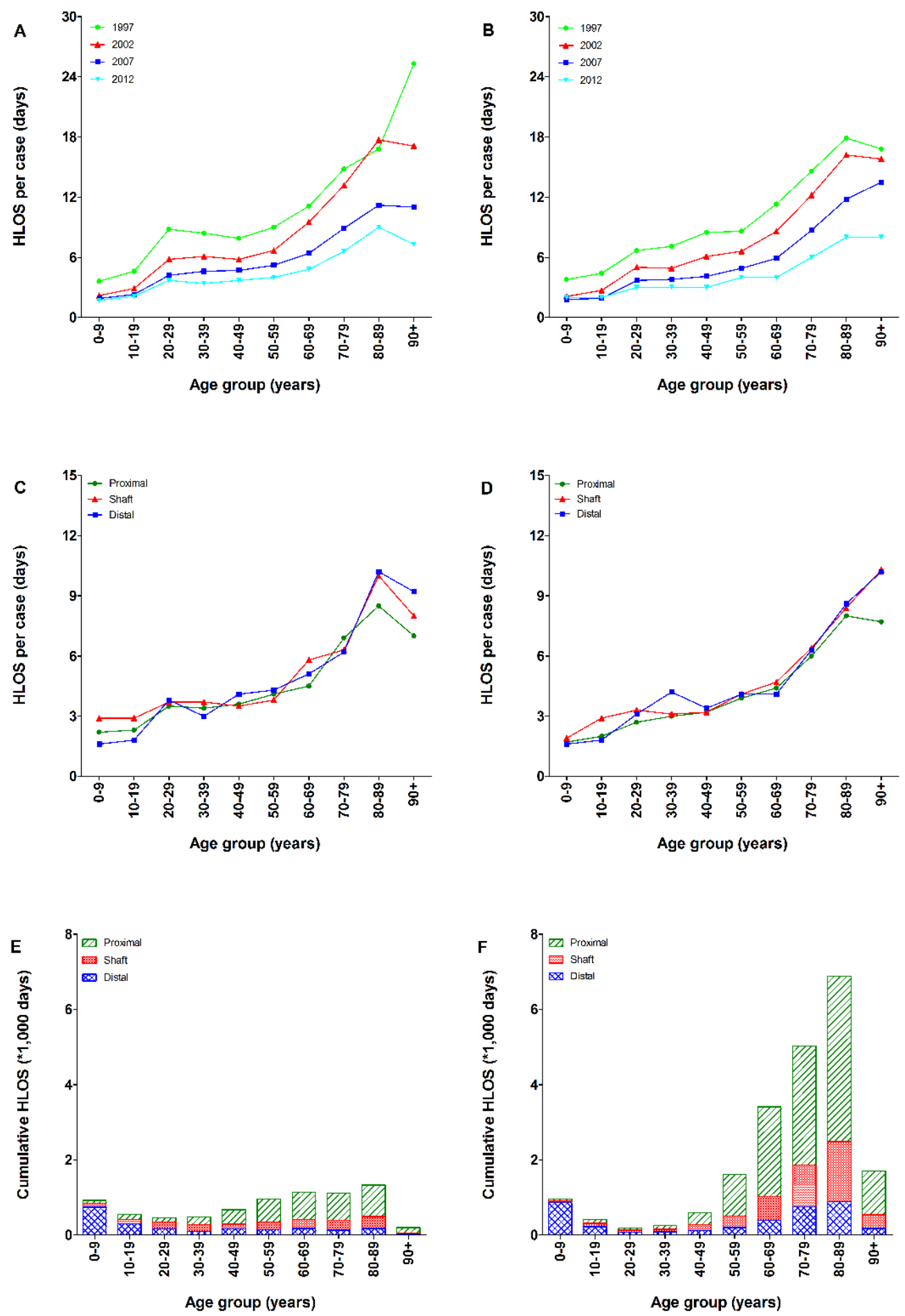
$2(\mathrm{~B}, \mathrm{D}, \mathrm{F})$ in proximal $(\mathrm{A}, \mathrm{B})$, shaft $(\mathrm{C}, \mathrm{D})$ and distal $(\mathrm{E}, \mathrm{F})$ humeral fractures in 2012

3 Costs are separated in different cost determinants.
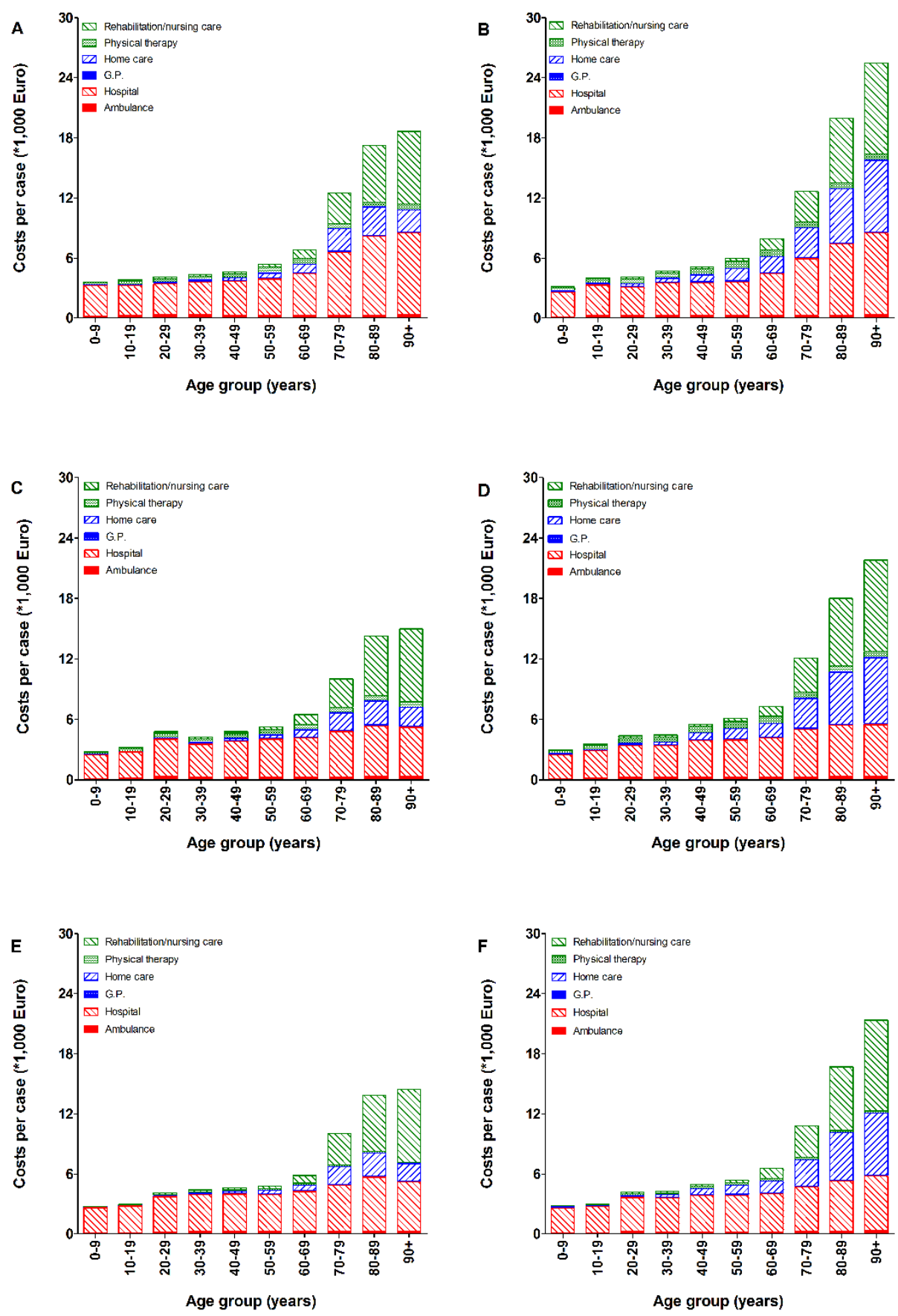
7 cost per case, the lower panels show cumulative costs for the entire study population.
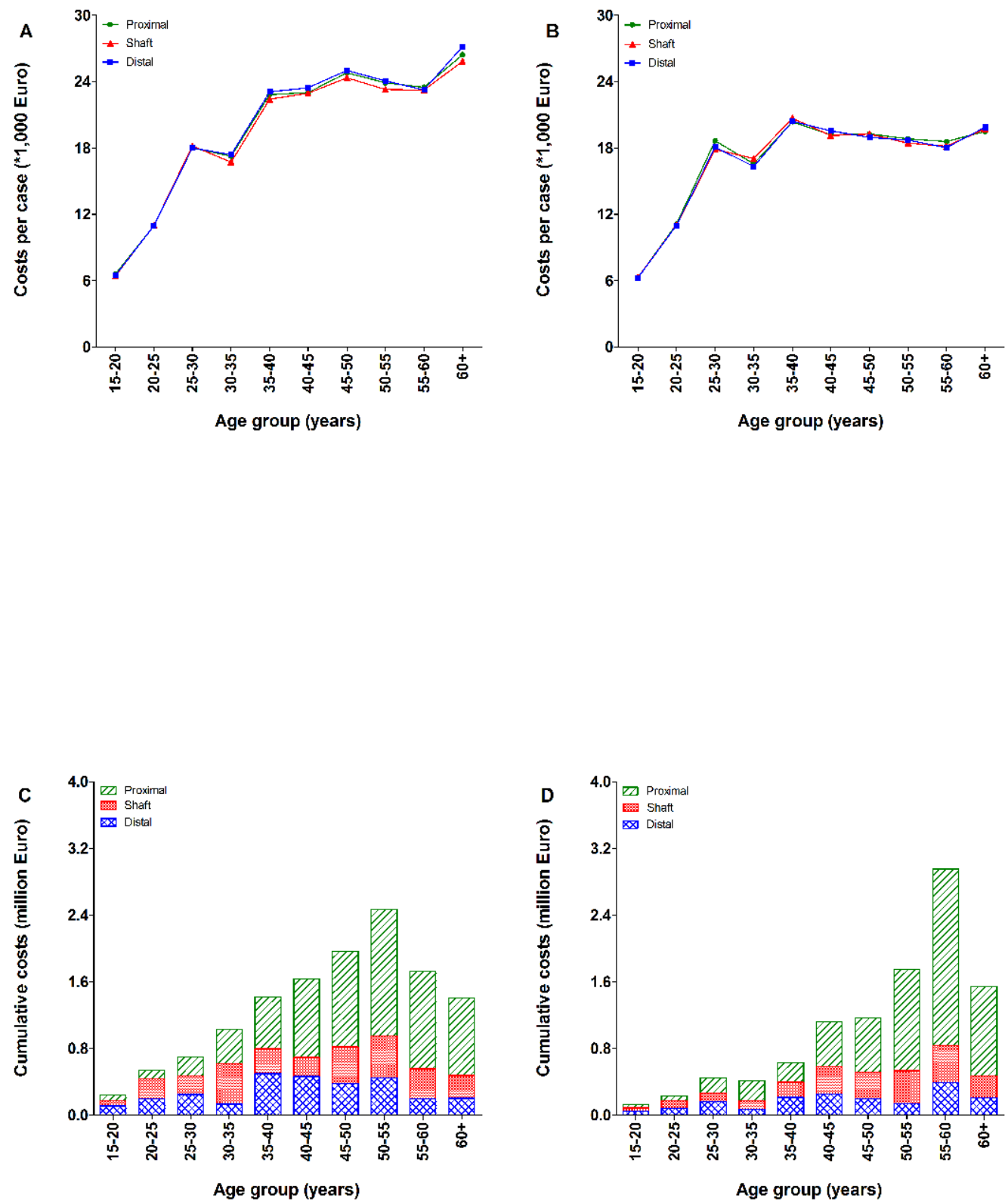